\title{
Methodological Reflection on the Co-Construction of Meaning within the South African Domestic Worker Sector: Challenging the Notion of "Voicelessness"
}

\author{
Christel Marais \\ Senior Lecturer, Department of Human Resource Management, \\ Vaal University of Technology, South Africa \\ christel@vut.ac.za

\section{Christo de W. Van Wyk} \\ Associate Professor, School of Behavioural Sciences, \\ North-West University, South Africa \\ Christo.VanWyk@nwu.ac.za
}

Doi:10.5901/mjss.2014.v5n20p726

\begin{abstract}
Globally the domestic worker sector is characterised by a sense of "voicelessness". Given the centrality of participant engagement within the interpretivist paradigm, accessing those with firsthand knowledge of the phenomena under investigation proved challenging. This is attributed to the institutionalised nature of the sector and the initial outsider status of the researchers. This article presents a transparent account of the methodological considerations that guided the co-construction of meaning within this context. Two thousand leaflets were distributed. By describing the intended study, inviting participation and providing assurances of confidentiality an initial rapport was established. Purposive, respondent-driven self-sampling resulted in 20 female participants employed as domestic workers. The pilot study indicated the value of using metaphors while exploring tentative topics. An interview guide facilitated the exploration of key concepts during our engagement. In-depth interviews were transcribed and analysed through an inductive process of data reduction. Rich, dense descriptive verbatim accounts of participants' lived realities confirmed data saturation. Emerging themes confirmed that the South African domestic worker sector is far from being voiceless if we are willing to listen. Making these voices heard constitutes a vital step in future efforts to empower this neglected sector of the labour market.
\end{abstract}

Keywords: phenomenology; research protocol; participant engagement; qualitative pilot study; meaning making; in-depth interview; domestic worker

\section{Introduction}

Participant engagement is crucial in qualitative research. Recognised as important research instruments, individual participants become co-constructors of the creation of meaning. Despite this assigned status, the value of establishing suitable research contacts before the beginning of the actual study is often underestimated in the research process (Witzel \& Reiter, 2012). By exploring the lived realities of domestic workers as the over arching objective of this study, we became aware of the unique challenges involved in finding willing participants from this sector of the South African labour force.

Marginalised and undervalued globally (ILO, 2013), the domestic worker sector is characterised by a sense of "voicelessness" among its members. Institutionalised over many decades within the South African context, this voicelessness is keenly portrayed in the artwork of world-renowned artist Mary Sibande. Sibande's upbringing was within the context of a family with a generational history of domestic workers. Her alter ego, Sophie-Ntombikayise (see Figure 1), provides a poignant and responsive social commentary on the daily realties faced by thousands of Black women within this work context (Balboa-Pöysti, 2011). 
Figure 1. Silent Symphony

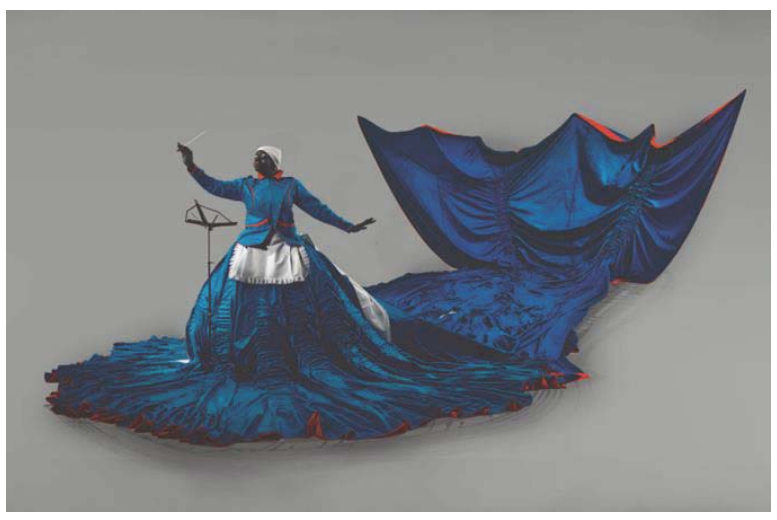

Figure 1. A depiction of the institutionalised limitations imposed upon generations of Black South African women who worked as domestic workers inspired by the artist's as well as the country's historical context. Adopted from the artwork entitled "Silent Symphony", archival print (Edition of 10), 90 x $60 \mathrm{~cm}$ (Sibande, 2010). Copyright 2010 by GallaryMOMO.

Throughout the ages, women, especially Black women, have suffered from historically entrenched stereotyping and myths (Few, Stephens, \& Rouse-Arnett, 2003). Recognising the perceived vulnerability associated with this segment of the South African labour force, the researchers felt that excluding them from their research efforts would mean, "ignoring those whom society needs to understand and serve" (Sieber \& Tolich, 2013, pp. 12-14). The research participants therefore were viewed as "historically, culturally and politically constructed entities with diverse identities" (Faircloth, 2012, p. 275). This view thus influenced how we conceived, approached, accessed and engaged with these individuals for data-generation purposes.

Employed within the context of a private house hold, domestic workers are faced with the complexities associated with an individualised employer-employee relationship characterised by power differentials. This apparent vulnerability and disempowerment associated with their employment relationship influenced our data-gathering efforts even further (Ali \& Kelly, 2012, p. 69). While wanting to tell their side of the story, the ever-present fear of losing their job should their employer become aware of their participation in a study of this nature inhibited the target population's readiness to engage. Accessing these silent voices thus proved to be a difficult endeavour.

According to Clark (2010), the development of a positive research relationship is crucial for a successful research engagement. This relationship has the potential to empower participants both at an individual level and at a collective level (Clark, 2010, pp. 404-416) when sharing their lived realities. Moreover, the establishment of a personal connection with potential participants enhances individuals' willingness to share their experiences with the researchers (Rubin \& Rubin, 2012). This implies the need for crossing the boundaries of engagement that transcend the mere acceptance by conversational partners in order to develop an understanding of their lived realities, which in this study differed markedly from our own worlds (Rubin \& Rubin, 2012, p. 75). Dimensions of race, colour, gender, status and power were acknowledged and undoubtedly influenced participant engagement from the first moment of establishing initial contact and were taken into consideration until the final write-up was concluded (Bloch, 2007; Few et al., 2003; Razon \& Ross, 2012).

Awareness linked to a specific phenomenon is the product of contextual factors (Griffin \& May, 2012) which implies the need to access those individuals that have firsthand knowledge of the phenomena under investigation. An active partnership of engagement between us, as the driving force of the research effort, and the participants who contributed to the study thus became essential. It was therefore important to understand and account for a number of different aspects that could potentially impede our interaction. With this in mind, we pursued an approach to participant recruitment and engagement whereby domestic workers were treated with courtesy and respect which in turn diluted the relevance of gender, race and social class as dimensions of power (Gillham, 2010). To enhance the trustworthiness of the study, this article will present a detailed and transparent account of considerations and actions taken while engaging with this largely invisible sector (Cock, 2011; Grossman, 2011) of the South African labour market. 


\section{Method}

The historical roots of qualitative research (Chilisa, 2012; Denscombe, 2011; Eatough, 2012; Lapan, Quartaroli, \& Riemer, 2012; Schwandt, 2003; Smith \& Eatough, 2012) bear testimony to the relevance of interpretivism as the chosen paradigm for this study. Research within the interpretivist paradigm aims to understand the complexity of uncovering the meaning associated with the human experience as voiced by participants (Hammond \& Wellington, 2013; Loseke, 2013, pp. 22-24). Studying human action as inherently meaningful is therefore directed at understanding and interpreting social actions (Schwandt, 2003, pp. 296-297). The practical implementation of this notion is evident in how participants were identified, approached, recruited, interviewed and understood as detailed below.

\subsection{Sampling}

\subsubsection{Initial recruitment efforts: Gaining access}

Participation is influenced by the recruitment methods used in a research project (Hill \& Nutt Williams, 2012). In order to persuade a vulnerable group such as members of the domestic worker sector to participate in the study, the context needed to be carefully considered. Locating and recruiting such individuals often requires some detective work (Rubin \& Rubin, 2012) such as making use of a gatekeeper (Byrne, 2012). Within the domestic worker sector, this gatekeeper is often the employer. Given the sensitive nature of the employment relationship in this sector, we did not make direct contact with any employers nor was any domestic worker approached at her place of employment during this study.

Building rapport starts from the first moment of making contact with the participant. Recognising that domestic workers are connected to a wider society, we opted for a flexible approach to the recruitment efforts. Deschaux-Beaume (2012) describes this as "real-life" recruitment characterised by researcher mobility in contrast to the more traditional recruitment strategies. With the aim of "getting a foot in the door", 2000 leaflets were handed out over a period of two months. These recruitment letters (Kaiser, 2009) were personally distributed at taxi ranks, on public transport and in passing within the geographically demarcated area of the study. Domestic workers, passengers and members of the public took the leaflets for distribution within their broader social networks.

The leaflets served as an "introductory letter" (Rubin \& Rubin, 2012) aiming to create a subjective interest in the focus of the study among potential participants. Affording them the option of making an informed choice, volunteers were requested to telephone the researchers in order to indicate their willingness to participate in the study. Englander (2012) alludes to the value of a brief preliminary meeting with the research participant prior to the commencement of the actual interview. The ability to establish, gain and maintain access to participants can affect all stages of the interviewerinterviewee relationship (Punch, 2011). Thus, despite the fact that most telephonic responses related to an urgent need to obtain employment or access legal advice related to labour issues within the sector, potential participants were recruited in this manner. Demographic diversity can also potentially influence participants' perceptions of the researchers, the development of a trusting relationship and their willingness to participate in the study. Obtaining individuals to participate in the study proved challenging. Participants cited a fear of losing their jobs as the main reason for not participating in the study during the time of the initial telephonic interaction and the actual interview.

\subsubsection{Participant recruitment}

The outcome of the research findings is evidently dependent upon those selected as participants (Rowley, 2012; Schutt, 2012). The overarching purpose of recruiting participants is to gather rich information rather than merely recruiting as many participants as possible (Layder, 2013). In terms of the established epistemology of this study, the collaboration between the researcher and those being researched was viewed as a crucial consideration in all sampling decisions (Atkins \& Wallace, 2012; Curtis \& Curtis, 2011; Punch, 2011). As a result, relationships were required that were responsive in nature and allowed for fluidity during participant engagement (Gillham, 2010).

Purposive sampling is especially relevant in the case of "hard-to-find" populations (Bernard, 2013). As sampling method it seeks to maximise the depth and richness of the data generated to address the research purpose (DiCiccoBloom \& Crabtree, 2006). Purposive, respondent-driven self-sampling was carried out to illustrate the phenomena under investigation. Inclusion criteria reflected the capacity of the participant to inform the research outcome (Quinlan, 2011). This implied membership of the population under investigation (South Africa, 2002), the ability to articulate experiences relating to the phenomena and a willingness to engage with the researchers (Kirkevold \& Bergland, 2007). Respondentdriven self-sampling reflected such a willingness to participate in the study (Daniel, 2012; Schensul, 2012; Seale, 2012). 
Although there is no universally agreed-upon sample size, according to Mears (2012), sample size is relative to the data being collected. There is growing consensus that 10 to 20 knowledgeable participants are enough to uncover and understand lived realities (Bernard, 2013; Smith \& Eatough, 2008). Quinlan (2011) describes a sample size of 20 as substantial. A total of 20 female participants employed as domestic workers, as defined by the legislative stipulations of Sectoral Determination 7 (South Africa, 2002), ultimately took part in the study. Participants ranged in age from 27 to 59 years. The average schooling level reported by participants was grade six, which is equivalent to a primary education. Although at times conversations were perceived as generating less noteworthy content in some cases, this could only be concluded upon closer analysis (Franklin, 2012). Despite the limited formal education among the members of this sector, this did not limit the richness of their shared experiences. The ultimate guide for the sample size, however, was the attainment of data saturation, when no new insights could be gained through continued exploration of the phenomena. By the $14^{\text {th }}$ interview the data saturation point was reached, and an additional two interviews were conducted to reconfirm the notion of data saturation (Quinlan, 2011).

\section{Data Collection}

\subsection{Interviewing as a data-gathering instrument}

In terms of the epistemological approach of this study, interview data represents but one of many possible representations of the world. The meaning is socially constructed through human activity and the agency which creates the social action (Borer \& Fontana, 2012; Hammond \& Wellington, 2013). Gibson and Brown (2009) describe this process as the creation of an analytically focussed discourse that provides insight into the lived experiences of those being studied. Regarded as an "ancient act", interviewing entails a meeting between two persons during which information and ideas are exchanged through questions and responses (Janesick, 2010, pp. 45-46). Glesne (2011, pp. 118-120) extends this analogy further by describing interviewing as a complex art of simultaneous happenings focussed on learning through dialogue. Delineated as a "socially grounded information source" (Deschaux-Beaume, 2012, p. 103), this interactive exchange results in communication and the joint construction of meaning about a specific topic which Bloch (2007) argues is a process of data generation rather than data collection.

Interviews as research instruments are regarded as appropriate for engaging with disadvantaged groups (Franklin, 2012) whose voices and experiences have been silenced in the past (Silverman, 2011). In-depth interviews are situated within the semi-structure part of the interview continuum (Franklin, 2012; Smith \& Eatough, 2012). They involve a one-onone interaction between a professional researcher and a consenting research participant (Zikmund, Babin, Carr, \& Griffin, 2013). Mears (2012, pp. 170-171) warns against the assumption that interviewing is easy. Differing from common conversations, in-depth interviews necessitate a purposeful engagement aimed at facilitating "insightful analysis and defensible findings". Although question-asking is central to any interview (Punch, 2011, p. 151), according to Franklin (2012, p. 191), interviews are "social acts, intersubjective and thereby often unpredictable". This real-time social interaction provided the researchers with an opportunity to follow up on and probe interesting issues raised while generating rich verbal accounts "without imposing any prior categorisation which might limit the field of enquiry" (Punch, 2011, p. 147). Accessing meaning was central to participant engagement. For this purpose the interviews were developmental in nature, questions could emerge, and even change as the situation dictated (Lapan et al., 2012). Understanding the phenomena under investigation depended upon this in-depth exploration of participants' personal accounts of their lived realities (Denscombe, 2011, pp. 99-100) and enhanced the overall trustworthiness of the study.

\subsection{Pre-pilot and pilot stage}

The literature warns against rushing into data collection activities unplanned (Atkins \& Wallace, 2012; Franklin, 2012; Gillham, 2010; Janesick, 2010). Despite this warning, we found the literature related to conducting a qualitative pilot study to be insufficiently descriptive and non-directional in nature. Dealing with our feelings of self-doubt and uncertainty as emerging qualitative researchers thus proved challenging during this phase. Despite the developmental nature of the chosen methodology, Leedy and Ormrod (2013) emphasise that qualitative research requires substantial preparation and planning. Moreover, Richards and Morse (2013, pp. 133-134) emphasise that interviewing necessitates "extraordinary interpersonal skills, a firm focus on the project's purposes, and solid theoretical knowledge". Interviewing as a research instrument therefore requires an awareness of the various sub-phenomena that could affect the outcome (Bloch, 2007). Since social science research is seldom conducted in settings designed for research (Gillham, 2010), consideration had to be given to how the research topic will be embraced by participants (Kim, 2010). For this reason, Gillham calls for a 
pre-pilot phase during which careful planning shapes the trial run of the project. Glesne (2011, pp. 109-110) describes this pre-pilot stage as a dynamic four-way interplay between the researcher, the tentative topic, the interview questions and the participant.

An initial interview guide was developed and refined by converting the research focus into questions that were meaningful for those being interviewed (Gillham, 2010; Hammond \& Wellington, 2013). Questions asked during this guided conversation related to the particular context in which the phenomena were experienced in an adaptive and flexible manner (Englander, 2012; Layder, 2013). The interview guide should not be viewed as a scripted list of questions but rather provided a case-centric adaptive and open format to prompt the exploration of the primary areas of interest of the study (Bloch, 2007; Curtis \& Curtis, 2011; Mears, 2012; Rowley, 2012; Smith \& Eatough, 2008).

Three one-on-one and one simultaneous (two-on-one) pilot interviews were conducted with five participants in diverse social settings. Each interview was subsequently self-transcribed and analysed by the interviewer prior to conducting the next interview to allow sufficient time for reflection and emerging issues to be fed back into further datacollection efforts (Cresswell, Morrison, Sheikh, Kalra, \& Coyne, 2012; Mears, 2012; Silverman, 2011). In addition, the data generated during the pilot study was not discarded for final analysis purposes since the data retained its value within this qualitative research effort (Bazeley, 2013). Although language could be viewed as a potential conversational barrier (Mears, 2012), an initial misinterpretation of one of the questions asked during the second pilot interview alluded to the application value of metaphors during participant engagement which added an additional dimension to this knowledgecreation process. Interviews were conducted in either English or Afrikaans, two of the official languages in South Africa (South Africa, 2012). Interview questioning was initially guided by both "upward and downward laddering" techniques enabling the participants to share their perceptions and accounts of their individual meaning-making processes (Easterby-Smith, Thorpe, \& Jackson, 2012, pp. 129-130; Zikmund et al., 2013). Confronted by the ever-present fear of possible job losses, as articulated by the participants, a re-envisioned approach to obtain informed consent was designed (Kaiser, 2009, pp. 9-10). Alleviating uncertainties expressed by participants in relation to the purpose of the research, their role, the consequences of their interaction with the researchers, freedom of choice and ultimately confidentiality became the focus.

The pilot study provided a "dress rehearsal" for the actual study in an "abbreviated form" (Chenail, 2011). It does not claim to solve all problems encountered in the research, but rather provided an effective way of assessing the feasibility of the planned research protocol while contending with the realities faced within the field (Aspers, 2009; Kim, 2010). The pilot study provided an insightful learning experience. This was an empowering, interactive and humbling developmental experience for the authors (Atkins \& Wallace, 2012; Bazeley, 2013; Bernard, 2013; Pezalla, Pettigrew, \& Miller-Day, 2012). These initial interviews represented great leaps forward in terms of the researchers' ability in skilled engagement (Johnson \& Rowlands, 2012). This in turn facilitated the development of an initial understanding of the concepts and theories held by the participants, the meanings they ascribed to them and how this informed their actions (Kociszewski, 2003; Maxwell, 2013).

\section{Data Generation}

\subsection{Interview design}

Data gathering from one person at a time is regarded as a defining characteristic of an in-depth interview (Curtis \& Curtis, 2011; Easterby-Smith et al., 2012; Hammond \& Wellington, 2013; Morehouse, 2012). As a core ingredient of social research, interviews usually occur between two persons (Franklin, 2012). Notwithstanding this notion, the tenure of the interview process is primarily the privilege of the interviewer as research instrument (Pezalla et al., 2012). This reflects an unequal distribution of power within the communicative relationship shaped during the interview (Henning, Van Rensburg, $\&$ Smit, 2005). The need for flexibility in the way the interview engagement was structured became evident during the pilot study. This was directly related to the entrenched characteristics of the South African domestic worker sector and the fear of losing their jobs that many participants expressed as a result of their willingness to verbalise their lived realities.

Chilisa (2012, pp. 204, 276-277) debates the relevance of conventional interview methods when exploring postcolonial social environments. Traditionally shaped by individualistic, westernised assumptions, the relevance of "communities' togetherness, cooperation and connectedness" is devalued. African women, Chilisa further comments, theorise about their lived experiences within a broader sociocultural context shaped by the principle of Ubuntu (being-forself-and-others) as an expression of their existence in relation to others (Murithi, 2006). Consideration was given to this sense of collectiveness and support among members of the target population while refining the interview format.

Interviews need not just take place on a one-to-one basis. Glesne (2011) alludes to the possibility of one or more 
interviewers and one or more interviewees participating in an interview. Easterby-Smith et al. (2012) extend this notion by describing group interviews as "loosely structured street conversations". These conversations generally refer to the researcher working with several individuals simultaneously (Punch, 2011). Data generation takes place from the interaction between participants within this context (Bell, 2010; DiCicco-Bloom \& Crabtree, 2006). Focus group interviews and group interviews are increasingly used interchangeably in literature. A defining characteristic of these methods is that the researcher needs to function more as a moderator or facilitator for the conversation than as an interviewer (Punch, 2011). This elicits a rich and broader range of experiences and differing opinions on the interview topic constructed through member interaction (Byrne, 2012; Carey \& Asbury, 2012). Multiparty interviewing, on the other hand, involves two or more interviewers or two or more interviewees simultaneously (Rubin \& Rubin, 2012, pp. 178-180). Multiparty interviews, however, have the potential for confusion and intimidation due to the complicated nature of the interaction. Despite this, such a joint interview can provide important value in its potential for new direction as voiced by those interviewed.

We, however, opted for what we refer to as a simultaneous interview format, in other words, a two-on-one interview. Although more than one participant was present during these interviews, this cannot be classified as a multipleperson or group interview since the focus was not on the interaction between the participants (Beitin, 2012). The interviewer remained the focal point of the communication and participants were interacted with as individuals, and not as a group, in order to explore their individual meaning-making (Denscombe, 2011; Smith \& Eatough, 2008). This is evident from the distinct voice of each participant throughout the interview interaction and resultant transcripts.

\subsection{Interview setting}

Participant engagement refers to more than the mere facilitation of a question and answer session. The interview setting is often the result of practical considerations rather than analytical (Gibson \& Brown, 2009). Convenience, availability and appropriateness are key concerns when setting up an interview (Glesne, 2011). Moreover, the potential impact of the research for both those researched and the researchers themselves was a deciding consideration (Dickson-Swift, James, Kippen, \& Liamputtong, 2007). With this in mind, scheduled interviews accommodated the personal preferences and availability of the participants as far as possible. This implied meeting after working hours, during their day off or alternatively over weekends. Interviews took place in a variety of physical settings; these included the domestic workers' own home or room, coffee shops, restaurants, conference venues and the first author's dining room. Access to relatively quiet environments was prioritised, not only to enhance the digital quality of the data recordings, but also to strengthen rapport-building efforts and reduce any perceived fear of victimisation by their employers. Seating arrangements were informal and the participants were encouraged to adapt them according to their personal preferences. Participants were familiarised with the data-recording equipment prior to the commencement of the interview, in particular with the lapel microphone which was used to amplify the audio quality (Glesne, 2011). In some cases, a friend-another fellow domestic worker-accompanied the participant to provide moral support but these individuals did not opt to share their meaning-making experiences and thus they were not noted as participants.

\subsection{Interview framework}

The initial interview interaction established a rapport between the interviewer and interviewee. The purpose and scope of the research was clearly stated and explained. Participants' concerns and questions were addressed prior to obtaining the signed consent forms from them. Data collection began by compiling a written account of participants' demographical information in field notes.

A non-descriptive and developmental interview guide provided a loose structure for questions around the developing themes (Bell, 2010; Easterby-Smith et al., 2012). Informed by the pilot study, the use of metaphors facilitated the accessibility and crystallisation of participants' lived realities in an engaging manner (Bazeley, 2013, pp. 117-118; Zikmund et al., 2013). Participants were encouraged to share their life stories without fear of prejudice around the following three broad metaphorical questions:

- If I were a young person sitting at your feet today asking you to tell me about your life as a domestic worker, what would you share with me?

- If you could write a letter to your employer today, what would the contents be?

- If you got on a bus and someone asked you about the labour laws affecting domestic workers in South Africa, what can you tell them?

As a "sensitising framework" the interview guide enhanced thematic engagement with the participants (Witzel \& 
Reiter, 2012). The process of empathetically engaging through ongoing dialogue brought about the co-construction of meaning. Griffin and May (2012) describe this relationship as "intersubjective" in nature. Engagement during the interview was furthermore always courteous and respectful in nature. If requested, questions were re-phrased or explained. Probing facilitated clarification of shared information during the interview (Gillham, 2010). Creswell (2013), however, underlines the value of being a good listener instead of a frequent speaker during an interview. Field notes were drafted shortly after an interview was concluded to ensure continuous engagement. Interviews were characterised by diverse outcomes; in some cases participants entered into the discussion with a predetermined agenda and in other cases establishing rapport proved to be arduous. Despite this, rich and dense descriptive accounts of their daily realities as domestic workers arose throughout the process of data generation.

A de-briefing conversation concluded each interview, focussing on the participant's feelings and needs that might have arisen as a result of our interaction. The value of their contribution was expressed and their availability for future engagement explored. Although the literature encourages the dissemination of the research findings to participants as an act of courtesy upon completion of the study (Bell, 2010; Kaiser, 2009), several participants declined this offer. On average, the interviews lasted 31 minutes with the shortest being 18 minutes and the longest being 62 minutes.

\section{Data Analysis}

\subsection{Preparing raw data for analysis}

Transcription is a time-consuming process, which needs to take place systematically and consistently. As an important part of the research process and not just a mere technical detail (McLellan, MacQueen, \& Neidig, 2003), transcription is largely dependent on the quality of the recorded interview. A naturalised approach to data transcription facilitated a detailed verbatim written account of the shared meaning-making process (Layder, 2013; Oliver, Serovich, \& Mason, 2005). Once the transcriptions had been made, they were interrogated for accuracy by listening to the recorded interview again and reading the transcription simultaneously (Tilley, 2003).

\subsection{Coding data and determining themes}

Qualitative data is non-numerical in nature and valued for its' richness, depth and complexity (Quinlan, 2011). This implies the needs for generating thick descriptions and analytical induction which stem from an observation and not a preestablished truth or assumption (Leedy \& Ormrod, 2013). Described as a multistep, sense-making endeavour (DeCuirGunby, Marshall, \& McCulloch, 2011), the actual coding process forms an integral part of data analysis. Chenail (2012b) describes the value of reading transcripts line by line but cautions against this as a coding strategy. Instead, he advocates the identification of meaningful, undivided units of analysis.

An interview produces a particular representation of participants' views and opinions (Bloch, 2007). Moreover, an open inductive approach is needed to make sense of the interview outcome (Hammond \& Wellington, 2013; Harding, 2013; Huy, 2012; Miles, Hunberman, \& Saldaña, 2014; Smith \& Eatough, 2012). It is also important for the researcher to become acquainted with the data recordings, transcript content and field notes to develop an emerged overview of the accounts of the participants of their lived realities (Clough \& Nutbrown, 2012). Through this approach the data was allowed to "speak for itself" during the early stages of data analysis (Rivas, 2012) and codes emerged from the data (Nieuwenhuis, 2011).

Data analysis is already a consideration at the conceptualisation phase of any phenomenological study. Characterised as a dynamic process (Witzel \& Reiter, 2012), data analysis prompts deeper thinking (Bazeley, 2009; Bergin, 2011). Gibson and Brown (2009, pp. 88-89) regard analysis as a "lived feature" of semi-structured interviews. Initially we felt overwhelmed and hemmed in by the vast amount of raw data collected during the participant engagement stage. We attribute this to the emerging nature of our engagement within the qualitative paradigm. Huy (2012) and Storey (2008) acknowledge that knowing how and where to start constitutes significant challenges during the data analysis stage of any research.

Saldaña (2013) describes coding as a value-adding, transitional process which facilitates the creative movement from the initial analysis to thematic abstractions from the data (Richards \& Morse, 2013, p. 151). Coding requires the researcher to have an open mind, especially during the early stages of analysis while assigning meaning to raw data (Bazeley, 2013). Layder (2013) emphasises the value of generating as many new ideas and codes as necessary to methodically reflect the data during this stage. Attentive reading of each transcript in conjunction with an initial process of "jotting" as described by Miles et al. (2014, pp. 93-95) characterised our initial coding efforts. This involved analytical 
handwritten field notes documenting initial thoughts and understanding as we interrogated the transcripts. These jotted ideas also informed the codes assigned to sections of transcribed data which could refer to as little as a single word or as much as an entire paragraph (Fade \& Swift, 2011).

Interview transcripts were subsequently imported into MAXQDA10, a qualitative data analysis software programme which required skilled engagement (MAXQDA, 1989-2013; Schutt, 2012). As a data management tool, MAXQDA10 proved vital in allowing the voice of the participants to be heard. Coding as a "circular process" allowed us to revisit the raw data "based upon theoretical findings and current research literature" (DeCuir-Gunby et al., 2011, p. 138). According to Bazeley (2013), the never-ending nature of coding reflects the need to code and recode until all the categories are saturated (see Figure 2).

Figure 2. Data Interpretation Process

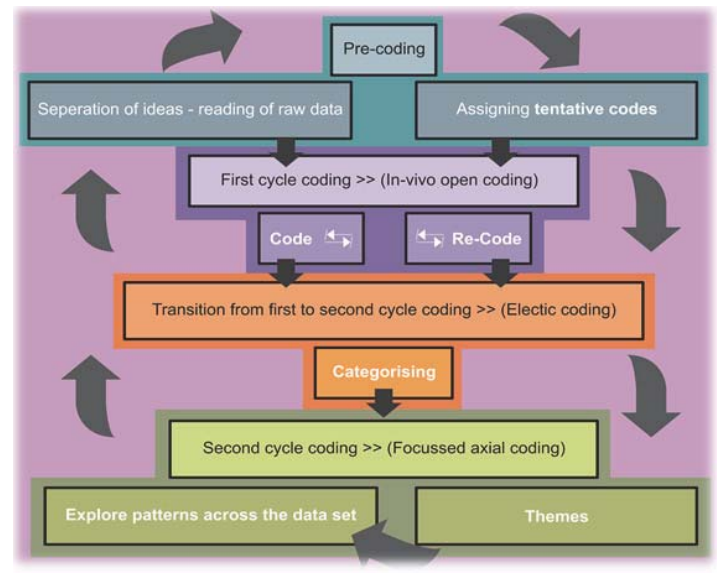

Figure 2. Iterative process of initial code generation, refinement through recoding, categorising of similar participant accounts and finally deriving themes. In-vivo open coding was applied during the initial stages of analysis. Themeing of the data was followed by a more eclectic coding strategy while progressing to the second cycle of coding. Focussed axial coding resulted in the identification of main themes within the data. Adapted from "The coding manual for qualitative researchers", by J. Saldaña (2013, pp. 58-66, 91-95, 175-183, 188-199, 213-223). Copyright 2013 by Sage Publications.

This circular transition, illustrated in Figure 2, implies a labour-intensive engagement with and emersion into the raw data. The study's dependability was enhanced through the establishment of a detailed audit trail. This implied retrievability of assigned codes, sections of data and analytic memos while creating the transition from the initial raw data to an interpretative thematic understanding of the phenomena. The seminal work by Tesch (1990) describes thematic analysis as an interpretative process aimed at revealing the phenomena under investigation. A slow and rigorous process of emersion into the data facilitated the crystallisation of shared understanding across participants' voiced experiences (Butler-Kisber, 2010). Warning against the dangers associated with deficiency or exuberance during the analytic process, Chenail (2012a) advocates allowing the data to say what the data says. This was a constant consideration during the entire data analysis process as illustrated in Figure 2.

A coding consistency check was done by an external, independent qualitative coder (Thomas, 2003). Not only was data saturation confirmed, but also the rich, dense and descriptive nature of the data was noted while assessing the trustworthiness of the data analysis. Due to the limited scope of this article, code frequencies will not be reported. Instead, refined themes supported by data are noted (Fade \& Swift, 2011). The three main themes related to:

- flourishing within a reciprocal caring employment relationship,

- work-life cycle and future directiveness; and

- awareness of labour legislation as an empowerment tool.

As naturalists, we did not ignore the literature to date. The aim was, however, to allow the themes to emerge from the data generated rather than being "overinfluenced" by what is already known (Rubin \& Rubin, 2012). The open-minded inductive approach of this study sought external validation through a process of purposeful literature engagement and 
control at the end of the study (Hammond \& Wellington, 2013). The literature support, which illustrates the inseparability of theory and practice, is aimed at putting the research into context of what is already known and published about the phenomena under investigation (Denscombe, 2010; Freeman, deMarrais, Preissle, Roulston, \& St. Pierre, 2007). Gallagher (2012, p. 70) describes this confirmation experience as the "phenomenological nod". Thus what was previously not confirmed but can be recognised is confirmed in this way. The findings relating to the main themes stated above as well as issues related to the trustworthiness and quality of the data analysis process will be presented in three follow-up articles.

\section{Researchers' Positionality}

Qualitative research is researcher-dependent which necessitates both initiator and facilitator skills as part of the researcher's repertory (Easterby-Smith et al., 2012; Leedy \& Ormrod, 2013; Zikmund et al., 2013). Monitoring researcher assumptions throughout the research process is, therefore, vital (Mears, 2012). This constant reflexivity is multi-layered; it encompasses the need for epistemological, ontological and methodological reflection at each stage of the research process (Haynes, 2012; Tracy, 2010). Witzel and Reiter (2012) regard the researcher's readiness to become involved in the participants' perspective as a crucial element while co-constructing meaning through interaction. We had to take a step back and purposefully re-consider our own implicit assumptions through critical self-scrutiny at every stage of the study (Bloch, 2007). According to Few et al. (2003, p. 210), there is a need for researchers to reconcile their "personal motivation for conducting research with a specific population and the extent of accountability owed to the population studied" through this process of self-reflexivity. A researcher's motivation to engage in a specific research study is thus never a naïve choice (Caelli, Ray, \& Mill, 2003). Acknowledging the possibility of researcher bias (Easterby-Smith et al., 2012), we opted for an empathetic and "radical listening" style characterised by honesty and integrity as advocated by Clough and Nutbrown (2012, pp. 99-100).

A mutual relationship can outlast the research period (Rubin \& Rubin, 2012). This is due, in part, to the complexity embedded in human social life while producing analytical accounts of social phenomena (Hammersley, 2008). Bloch (2007) cautions against the transition that can take place where a good rapport has been established during the interview, and this then transmutes into a counselling session. Moreover, the accounts shared during some situations can be so painful that it becomes impossible at times to maintain a neutral façade (Bernard, 2013). The physical and emotional toll this could potentially take on the researcher self should not be disregarded (Denscombe, 2010; DicksonSwift, James, Kippen, \& Liamputtong, 2008; Rubin \& Rubin, 2012). Bearing in mind the sacrifices participants had to make in order to take part in the study, we were confronted by the question of reciprocity within this research relationship (Clark, 2010). Having transcended the position of an outsider to that of an insider during the course of our engagement (Berger, 2013) we had to consider what would happen to the participants once the researcher left (Ali \& Kelly, 2012). In this regards, Denscombe (2010) airs a word of caution based on the implications of prolonged relationships necessitating personal involvement. These considerations thus necessitated a sensitivity to the broader social context of the participants throughout our engagement (Schutt, 2012).

Sincerity, as an end goal, was pursued as we entered the lives of others (Dickson-Swift et al., 2007; Tracy, 2010). Subscribing to the notion that the research interview should not be mistaken for a therapeutic setting (Gillham, 2010), we overtly stated the purpose of the research and the researchers' role within this context. Upon completion of the research interview, participants were presented with a copy of Sectoral Determination 7: Domestic worker sector (South Africa, 2002) detailing their rights as domestic workers. Consideration was also given to any questions they had with regard to their current employment conditions. The researcher-participant relationship did, however, not extend beyond the research period.

\section{Ethical Considerations during Participant Engagement}

Underpinned by morals, ethics is an integral part of every step of the research process within a specific research context (Alderson \& Marrow, 2011; Biggam, 2012; Hammond \& Wellington, 2013, pp. 59-60; Silverman, 2011). Professional integrity within this study related to the need for and commitment to ethically conducted research (Ali \& Kelly, 2012; Harding, 2013, pp. 24-27; Holt, 2012, p. 102). As an interwoven aspect of each step in the research process, this implied a moral responsibility on the part of the researchers towards the participants and future social research efforts.

Embedded in the notion of voluntary participation is that there is no obligation for any individual to participate in a research project. Seeking informed consent during the initial stages of participant engagement provided the participants with an opportunity to query the meaning and implications of their participation (Bell, 2010). Carey and Asbury (2012) 
argue that incentivising participation in the research project should be planned with the target population in mind. Financial reimbursement was thus limited to the travelling costs incurred by the domestic workers to meet the researchers.

\section{Conclusion}

The application value of qualitative research for future decision-making is imbedded in an appropriate design, execution and reporting of the study (Tong, Sainsburry, \& Craig, 2007). "Methodological mastery" proved to be vital at each stage of this research study and guided participant engagement throughout the study (Huy, 2012, p. 285). This shared relationship bridged the "space between" those being researched and those doing the research through circled engagement (Corbin Dwyer \& Buckle, 2009). As co-creators of knowledge both the researchers and the participants entered into a trusting relationship (Rubin \& Rubin, 2012). The vulnerability inherently associated with the domestic worker sector is not transient in nature. The challenge was to move beyond the mere gathering of facts to allowing the participants' "authentic voice" to be heard (Atkins \& Wallace, 2012, p. 88). Engaging those involved in a specific phenomenon can challenge entrenched assumptions and ways of doing by portraying ongoing social processes. The South African domestic worker sector, far from being voiceless if we are only willing to listen, provides researchers with a wealth of investigation possibilities. Making these voices heard constitutes a critical step in future empowerment efforts within this sector of the labour market.

\section{Acknowledgements}

This work is based on the research supported in part by the National Research Foundation of South Africa (UNIQUE GRANT NO 86484). The opinions, findings and conclusions or recommendations expressed in this article are those of the author/s for which the NRF accepts no liability whatsoever.

\section{References}

Alderson, P., \& Marrow, V. (2011). The ethics of research with children and young people: A practical handbook. London, England: Sage.

Ali, S., \& Kelly, M. (2012). Ethics and social research. In C. Seale (Ed.), Researching Society and Culture (3rd ed., pp. 59-75). Thousand Oaks, CA: Sage.

Aspers, P. (2009). Empirical phenomenology: A qualitative research approach. The Indo-Pacific Journal of Phenomenology, 9(2), 1-12.

Atkins, L., \& Wallace, S. (2012). Qualitative research in education. Thousand Oaks, CA: Sage.

Balboa-Pöysti, R. (2011). Mary Sibanda: Dressed to tell South Africa's tale. Retrieved from http://ruxandrap.wordpress.com/2011/11/25/mary-sibande-dress-to-tell-south-africas-tale/

Bazeley, P. (2009). Analysing qualitative data: More than 'identifying themes'. Malaysian Journal of Qualitative Research, 2, 6-22.

Bazeley, P. (2013). Qualitative data analysis: Practical strategies. Thousand Oaks, CA: Sage.

Beitin, B. K. (2012). Interview and sampling: How many and whom. In J. F. Gubrium, J. A. Holstein, A. B. Marvasti \& K. D. McKinney (Eds.), The SAGE handbook of interview research: The complexity of the craft (2nd ed., pp. 243-253). Thousand Oaks, CA: Sage.

Bell, J. (2010). Doing your research project: A guide for first-time researchers in education, health and social science (5th ed.). Berkshire, England: McGraw-Hill.

Berger, R. (2013). Now I see it, now I don't: Researcher's position and reflexivity in qualitative research. Qualitative Research, 1-16. doi: $10.1177 / 1468794112468475$

Bergin, M. (2011). NVivo 8 and consistency in data analysis: Reflecting on the use of a qualitative data analysis program. Nurse Researcher, 18(3), 6-12.

Bernard, H. R. (2013). Social research methods: Qualitative and quantitative approaches (2nd ed.). Thousand Oaks, CA: Sage.

Biggam, J. (2012). Succeeding with your Master's dissertation: A step-by-step handbook (2nd ed.). Berkshire, England: McGraw-Hill.

Bloch, A. (2007). Doing social surveys. In C. Seale (Ed.), Researching society and culture (2nd ed., pp. 163-177). Thousand Oaks, CA: Sage.

Borer, M. I., \& Fontana, A. (2012). Postmodern trends: Expanding the horizons of interviewing practices and epistemologies. In J. F. Gubrium, J. A. Holstein, A. B. Marvasti \& K. D. McKinney (Eds.), The SAGE handbook of interview research: The complexity of the craft (2nd ed., pp. 45-60). Thousand Oaks, CA: Sage.

Butler-Kisber, L. (2010). Qualitative inquiry: Thematic, narrative and arts-informed perspectives. Thousand Oaks, CA: Sage.

Byrne, B. (2012). Qualitative interviewing. In C. Seale (Ed.), Researching society and culture (2nd ed., pp. 207-220). Thousand Oaks, CA: Sage.

Caelli, K., Ray, L., \& Mill, J. (2003). "Clear as mud": Towards greater clarity in generic qualitative research. International Journal of 
Qualitative Methods, 2(2), 1-13.

Carey, M. A., \& Asbury, J. (2012). Focus group research. Walnut Creek, CA: Left Coast Press.

Chenail, R. J. (2011). Interviewing the investigator: Strategies for addressing instrumentation and researcher bias concerns in qualitative research. The Qualitative Report, 16(1), 255-262.

Chenail, R. J. (2012a). Conducting qualitative data analysis: Managing dynamic tensions within. The Qualitative Report, 17(2), 500-505.

Chenail, R. J. (2012b). Conducting qualitative data analysis: Reading line-by-line, but analysing by meaningful qualitative units. The Qualitative Report, 17(1), 266-269.

Chilisa, B. (2012). Indigenous research methodologies. California, CA: Sage.

Clark, T. (2010). On "being researched": Why people engage with qualitative research? Qualitative Research, 10(4), 399-419. doi: $10.1177 / 1468794110366796$

Clough, P., \& Nutbrown, C. (2012). A student's guide to methodology (3rd ed.). London, England: Sage.

Cock, J. (2011). Challenging the invisibility of domestic workers. South African Review of Sociology, 42(2), 132-133. doi: 10.1080/21528586.2011.582743

Corbin Dwyer, S., \& Buckle, J. L. (2009). The space between: On being an insider-outsider in qualitative research. International Journal of Qualitative Methods, 8(1), 54-63.

Cresswell, K., Morrison, Z., Sheikh, A., Kalra, D., \& Coyne, J. (2012). "There are too many, but never enough": Qualitative case study investigating routine coding of clinical information in depression. PLOS ONE, 7(8), 1-10. doi: 10.1371/journal.pone.0043831

Creswell, J. W. (2013). Qualitative inquiry and research design: Choosing among five approaches (3rd ed.). Thousand Oaks, CA: Sage.

Curtis, B., \& Curtis, C. (2011). Social research: A practical introduction. London, England: Sage.

Daniel, J. (2012). Sampling essentials: Practical guidelines for making sampling choices. Thousand Oaks, CA: Sage.

DeCuir-Gunby, J. T., Marshall, P. L., \& McCulloch, A. W. (2011). Developing and using a codebook for the analysis of interview data: An example from a professional development research project. Field Methods, 23(2), 136-155. doi: 10.1177/1525822X10388468

Denscombe, M. (2010). Ground rules for social research: Guidelines for good practice (2nd ed.). Berkshire, England: McGraw-Hill.

Denscombe, M. (2011). The good research guide for small-scale social research projects (4th ed.). Berkshire, England: McGraw-Hill.

Deschaux-Beaume, D. (2012). Investigating the military field: Qualitative research strategy and interviewing. Current Sociology, 60(1), 101-117. doi: 10.1177/0011392111426656

DiCicco-Bloom, B., \& Crabtree, B. F. (2006). The qualitative research interview. Medical Education, 40, 314-321. doi: 10.1111/j.13652929.2006.02418.x

Dickson-Swift, V., James, E. L., Kippen, S., \& Liamputtong, P. (2007). Doing sensitive research: What challenges do qualitative researchers face? Qualitative Research, 7, 327-353. doi: 10.1177/1468794107078515

Dickson-Swift, V., James, E. L., Kippen, S., \& Liamputtong, P. (2008). Risk to researchers in qualitative research on sensitive topics: Issues and strategies. Qualitative Health Research, 18(1), 133-144. doi: 10.1177/1049732307309007

Easterby-Smith, M., Thorpe, R., \& Jackson, P. (2012). Management research (4th ed.). Thousand Oaks, CA: Sage.

Eatough, V. (2012). Introduction to qualitative methods. In G. M. Breakwell, J. A. Smith \& D. B. Wright (Eds.), Research methods in psychology (4th ed., pp. 321-342). Thousand Oaks, CA: Sage.

Englander, M. (2012). The interview: Data collection in descriptive phenomenological human scientific research. Journal of Phenomenological Psychology, 43, 13-35. doi: 10.1163/156916212X632943

Fade, S. A., \& Swift, J. A. (2011). Qualitative research in nutrition and dietetics: Data analysis issues. Journal of Human Nutrition and Dietetics, 24(2), 106-114. doi: 10.1111/j.1365-277X.2010.01118.x

Faircloth, C. A. (2012). After the interview: What is left at the end. In J. F. Gubrium, J. A. Holstein, A. B. Marvasti \& K. D. McKinney (Eds.), The SAGE handbook of interview research: The complexity of the craft (2nd ed., pp. 269-277). Thousand Oaks, CA: Sage.

Few, A. L., Stephens, D. P., \& Rouse-Arnett, M. (2003). Sister-to-sister talking: Transcending boundaries and challenges in qualitative research with Black women. Family Relations, 52(3), 205-215.

Franklin, M. I. (2012). Understanding research: Coping with the quantitative-qualitative devide. New York, NY: Routledge.

Freeman, M., deMarrais, K., Preissle, J., Roulston, K., \& St. Pierre, E. A. (2007). Standards of evidence in qualitative research: An incitement to discourse. Educational Researcher, 36(1), 25-32. doi: 10.3102/0013189X06298009

Gallagher, S. (2012). Phenomenology. New York, NY: Palgrave Macmillan.

Gibson, W. J., \& Brown, A. (2009). Working with qualitative data. Thousand Oaks, CA: Sage.

Gillham, B. (2010). Research interviewing: The range of techniques. Berkshire, England: Open University Press.

Glesne, C. (2011). Becoming qualitative researchers: An introduction (4th ed.). Boston, MA: Pearson.

Griffin, M., \& May, V. (2012). Narrative analysis and interpretative phenomenological analysis. In C. Seale (Ed.), Researching society and culture (3rd ed., pp. 422-457). Thousand Oaks, CA: Sage.

Grossman, J. (2011). The researched on research and researchers: Conversations with SADSAWU. South African Review of Sociology, 42(2), 122-127. doi: 10.1080/21528586.2011.582744

Hammersley, M. (2008). Questioning qualitative enquiry. Thousand Oaks, CA: Sage.

Hammond, M., \& Wellington, J. (2013). Research methods: The key concepts. New York, NY: Routledge.

Harding, J. (2013). Qualitative data analysis from start to finish. Thousand Oaks, CA: Sage.

Haynes, K. (2012). Reflexivity in qualitative research. In G. Symon \& C. Cassell (Eds.), Qualitative organisational research: Core methods and current challenges (pp. 72-89). Thousand Oaks, CA: Sage. 
Henning, E., Van Rensburg, W., \& Smit, B. (2005). Finding your way in qualitative research. Pretoria, South Africa: Van Schaik.

Hill, C. E., \& Nutt Williams, E. (2012). The sample. In C. E. Hill (Ed.), Consensual qualitative research: A practical resource for investigating social science phenomena (pp. 71-81). Washington, DC: American Psychological Association.

Holt, R. (2012). Ethical research practice. In G. Symon \& C. Cassell (Eds.), Qualitative organisational research: Core methods and current challenges (pp. 90-108). Thousand Oaks, CA: Sage.

Huy, Q. N. (2012). Improving the odds of publishing inductive qualitative research in premier academic journals. Journal of Applied Behavioral Science, 48(2), 282-287. doi: 10.1177/0021886312438864

ILO. (2013). Domestic workers across the world: Global and regional statistics and the extent of legal protection (pp. 1-146). Geneva: International Labour Office.

Janesick, V. J. (2010). Oral history for the qualitative researcher: Choreographing the story. New York, NY: Guilford Press.

Johnson, J. M., \& Rowlands, T. (2012). The interpersonal dynamics of in-depth intervieweing. In J. F. Gubrium, J. A. Holstein, A. B. Marvasti \& K. D. McKinney (Eds.), The SAGE handbook of interview research: The complexity of the craft (pp. 99-113). Thousand Oaks, CA: Sage.

Kaiser, K. (2009). Protecting respondent confidentiality in qualitative research. Qualitative Health Research, 19(11), 1632-1641. doi: $10.1177 / 1049732309350879$

Kim, Y. (2010). The pilot study in qualitative inquiry: Identifying issues and learning lessons for culturally competent research. Qualitative Social Work, 10(2), 190-206. doi: 10.1177/1473325010362001

Kirkevold, M., \& Bergland, A. D. (2007). The quality of qualitative data: Issues to consider when interviewing participants who have difficulties providing detailed accounts of their experiences. International Journal of Qualitative Studies on Health and Well-being, 2, 68-75. doi: 10.1080/17482620701259273

Kociszewski, C. (2003). A phenomenological pilot study of the nurses' experience providing spiritual care. Journal of Holistic Nursing, 21(2), 131-148. doi: 10.1177/0898010103021002004

Lapan, S. D., Quartaroli, M. T., \& Riemer, F. J. (2012). Introduction to qualitative research. In S. D. Lapan, M. T. Quartaroli \& F. J. Riemer (Eds.), Qualitative research: Introduction to methods and designs (pp. 3-18). San Francisco, CA: Jossey-Bass.

Layder, D. (2013). Doing excellent small-scale research. Thousand Oaks, CA: Sage.

Leedy, P. D., \& Ormrod, J. E. (2013). Practical research: Planning and design (10th ed.). Upper Saddle River, NJ: Pearson.

Loseke, D. R. (2013). Methodological thinking: Basic principles of social science design. Thousand Oaks, CA: Sage.

MAXQDA. (1989-2013). MAXQDA, software for qualitative data analysis. Berlin, Germany: VerbiSoftware

Maxwell, J. A. (2013) Qualitative research design: An interactive approach. Applied social research methods series: Vol. 41 (3rd ed.). Thousand Oaks, CA: Sage.

McLellan, E., MacQueen, K. M., \& Neidig, J. L. (2003). Beyond the qualitative interview: Data preparation and transcription. Field Methods, 15(1), 63-84. doi: 10.1177/1525822X02239573

Mears, C. L. (2012). In-depth interviews. In J. Arthur, M. Waring, R. J. Coe \& L. V. Hedges (Eds.), Research methods and methodologies in education (pp. 170-176). Thousand Oaks, CA: Sage.

Miles, B. M., Hunberman, A. M., \& Saldaña, J. (2014). Qualitative data analysis: A methods sourcebook (3rd ed.). Thousand Oaks, CA: Sage.

Morehouse, R. E. (2012). Beginning interpretative inquiry: A step-by-step approach to research and evaluation. New York, NY: Routledge.

Murithi, T. (2006). Practical peacemaking wisdom from Africa: Reflections on Ubuntu. Journal of Pan African Studies, 1(4), 25-34.

Nieuwenhuis, J. (2011). Analysing qualitative data. In K. Maree (Ed.), First steps in research (pp. 99-118). Pietermaritzburg, South Africa: Van Schaik.

Oliver, D. G., Serovich, J. M., \& Mason, T. L. (2005). Constraints and opportunities with interview transcription: Towards reflection in qualitative research. Social Forces, 84(2), 1273-1289.

Pezalla, A. E., Pettigrew, J., \& Miller-Day, M. (2012). Researching the researcher-as-instrument: An exercise in interviewer selfreflexivity. Qualitative Research, 12(2), 165-185. doi: 10.1177/1468794111422107

Punch, K. F. (2011). Introduction to research methods in education. London, England: Sage.

Quinlan, C. (2011). Business research methods. Hampshire, England: Cengage.

Razon, N., \& Ross, K. (2012). Negotiating fluid identities: Alliance-building in qualitative interviews. Qualitative Inquiry, 18(6), 494-503. doi: $10.1177 / 1077800412442816$

Richards, L., \& Morse, J. M. (2013). Readme first for a user's guide to qualitative methods (3rd ed.). Thousand Oaks, CA: Sage.

Rivas, C. (2012). Coding and analysing qualitative data. In C. Seale (Ed.), Researching society and culture (3rd ed., pp. 368-382). Thousand Oaks, CA: Sage.

Rowley, J. (2012). Conducting research interviews. Management Research Review, 35(3), 260-271. doi: 10.1108/01409171211210154

Rubin, H. J., \& Rubin, I. (2012). Qualitative interviewing: The art of hearing data (3rd ed.). Thousand Oaks, CA: Sage.

Saldaña, J. (2013). The coding manual for qualitative researchers (2nd ed.). Thousand Oaks, CA: Sage.

Schensul, J. J. (2012). Methodology, methods, and tools in qualitative research. In S. D. Lapan, M. T. Quartaroli \& F. J. Riemer (Eds.), Qualitative research: Introduction to methods and design (pp. 69-103). San Francisco, CA: Jossey-Bass.

Schutt, R. K. (2012). Investigating the social world: The process and practice of research (7th ed.). Thousand Oaks, CA: Sage.

Schwandt, T. A. (2003). Three epistemological stances for qualitative inquiry: Interpretivism, hermeneutics and social constructionism. In N. K. Denzin \& Y. S. Lincoln (Eds.), The landscape of qualitative research: Theories and issues (2nd ed., pp. 292-330). 
Thousand Oaks, CA: Sage.

Seale, C. (2012). Sampling. In C. Seale (Ed.), Researching society and culture (3rd ed., pp. 136-150). Thousand Oaks, CA: Sage.

Sibande, M. (2010). Silent symphony (pp. Archival print ). Johannesburg, South Africa: GalleryMOMO.

Sieber, J. E., \& Tolich, M. B. (2013). Planning ethically responsible research (2nd ed.). Thousand Oaks, CA: Sage.

Silverman, D. (2011). Interpreting qualitative data (4th ed.). London, England: Sage.

Smith, J. A., \& Eatough, V. (2008). Interprative phenomenological analysis. In E. Lyons \& A. Coyle (Eds.), Analysing qualitative data in psychology (pp. 35-50). Thousand Oaks, CA: Sage.

Smith, J. A., \& Eatough, V. (2012). Interpreting phenomenological analysis. In G. M. Breakwell, J. A. Smith \& D. B. Wright (Eds.), Research methods in psychology (4th ed., pp. 439-459). Thousand Oaks, CA: Sage.

South Africa. (2002). Sectoral Determination 7: Domestic Worker Sector, South Africa. (23732). Cape Town, South Africa: Government Gazette.

South Africa. (2012). Act no. 12 of 2012: Use of Official Languages Act, 2012. (35742). Cape Town, South Africa: Government Gazette.

Storey, L. (2008). Doing interpretative phenomenological analysis. In E. Lyons \& A. Coyle (Eds.), Analysing qualitative data in psychology (pp. 51-64). Thousand Oaks, CA: Sage.

Tesch, R. (1990). Qualitative research: Analysis types and software tools. Abingdon, England: Routledge.

Thomas, D. R. (2003). A general inductive approach for qualitative data analysis. Paper presented at the School of Population Health, University of Auckland, Auckland, New Zealand.

Tilley, S. A. (2003). "Challenging" research practice: Turning a critical lens on the world of transcription. Qualitative Inquiry, 9(5), 750773. doi: $10.1177 / 1077800403255296$

Tong, A., Sainsburry, P., \& Craig, J. (2007). Consolidated criteria for reporting qualitative research (COREQ): A 32-item checklist for interview and focus groups. International Journal for Quality in Health Care, 19(6), 349-357. doi: 10.1093/intqhc/mzm042

Tracy, S. J. (2010). Qualitative quality: Eight "big-tent" criteria for excellent qualitative research. Qualitative Inquiry, 16(10), 837-851. doi: 10.1177/1077800410383121

Witzel, A., \& Reiter, H. (2012). The problem-centred interview. Thousand Oaks, CA: Sage.

Zikmund, W. G., Babin, B. J., Carr, J. C., \& Griffin, M. (2013). Business research methods (9th ed.). Manson, OH: Cengage. 